\title{
Tobacco use is increasing in popular films
}

\author{
Theresa F Stockwell, Stanton A Glantz
}

\begin{abstract}
Objective-To study the presentation of smoking in motion pictures.

Design-This study examined tobacco use in a random sample of five of the top 20 grossing films each year from 1990-1996 and combined these data with our earlier study of tobacco use in films that covered 1960-1990.

Main outcome measures-Rate of tobacco use per minute of film, characters who are smoking, motivation to smoke.

Results-The overall rate of tobacco use appears to have "bottomed out" in the 1980 s and is now increasing back to levels observed in the 1960s. The presentation of tobacco use in films is increasingly discordant with reality, because tobacco use in the population continues to drop. Films continue to portray smokers as successful white males, although portrayal of smoking among women is increasing.

Conclusions-The gap between the representation of tobacco use in films and the reality of tobacco continues to widen, with the prevalence of smoking among lead characters four times the smoking prevalence among comparable individuals in society at large.
\end{abstract}

(Tobacco Control 1997;6:282-284)

Keywords: tobacco use, cigarettes, films

\section{Introduction}

Movies both shape and reflect social values regarding tobacco use. Previously ${ }^{1}$ we studied a random sample of 62 motion pictures released between 1960 (before the US Surgeon General's first report on smoking and health ${ }^{2}$ ) through 1990 and found that the overall rate of tobacco events per minute of film had remained constant throughout this period, despite a major decline in tobacco use among the public during the same period..$^{3-9}$ Although there was a decline in smoking by major characters in films over the three decades we studied, it was still roughly three times as prevalent as in comparable groups in the society at large. We also found that the images associated with tobacco use in the movies-power, autonomy, and success-were more consonant with the imagery of tobacco advertising than with the reality of tobacco use. Since publication of our earlier work, the news media ${ }^{10-15}$ have called attention to an apparent increase in tobacco use in the movies. This study extends our ear- lier work ${ }^{1}$ by adding a random sample of films released between 1990 and 1996.

\section{Methods}

The methods used in this study are similar to those of our earlier report ${ }^{1}$ and will be summarised briefly here. Five feature-length films were selected at random from the top 20 gross- 9 ing films each year. ${ }^{16-21}$ For 1990, we used the two films included in our previous study, ${ }^{1}$ plus three more films drawn at random. We constructed the random sample by using Minitab to generate a list of random numbers between one and 20 , then took the top five numbers. The films were numbered according to box office gross receipts, then the movies corresponding to the five random numbers were analysed. The films selected for study were viewed in random order. We obtained all the films on video cassette.

The films were viewed in five-minute $\vec{\nexists}$ increments to identify "tobacco events", including implied or actual consumption of tobacco, paraphernalia (ashtrays and matches), talking about tobacco, and tobacco product logos. Antitobacco events included no-smoking signs and discussion about the dangers of tobacco use. (For example, comments such as "It's my only vice" (Cape Fear) are negative portrayals of tobacco whereas one scene showing relaxing $\underline{0}$ with a cigar after a family dinner (Scent of $a$; Woman) is a positive portrayal.) A scene is defined as any frame, implied or actual, that $\delta$ depicts a continuous interchange. When the continuum is broken by a different scene and $\frac{9}{5}$ returns to the original scene, it is counted as a $D$ separate incident. Other variables recorded were: gender, age, ethnicity, character (such as 응 protagonist), character role (for example, $N$ attorney), type of scene (such as stressful or dangerous, relaxation). Additionally, incident location, length used per incident (in seconds), reaction to use (positive or $\stackrel{\circ}{\circ}$ negative), and presence of a minor in the scene, were recorded. All films were coded 0 by a single person (TFS); we used this $\overrightarrow{0}$ approach because our earlier study ${ }^{1}$ showed $\stackrel{\odot}{\circ}$ good agreement between two independent $\stackrel{\otimes}{\stackrel{\circ}{\circ}}$ reviewers.

We examined the rate of tobacco events per minute of film (excluding credits) at which tobacco events occurred to account for the fact that films have shortened over time. To test for changes over time from decade to decade, we used two-way contingency tables analysed with the $\chi^{2}$ test. The unit of analysis was the tobacco event. (In our earlier study, 1990 was considered 


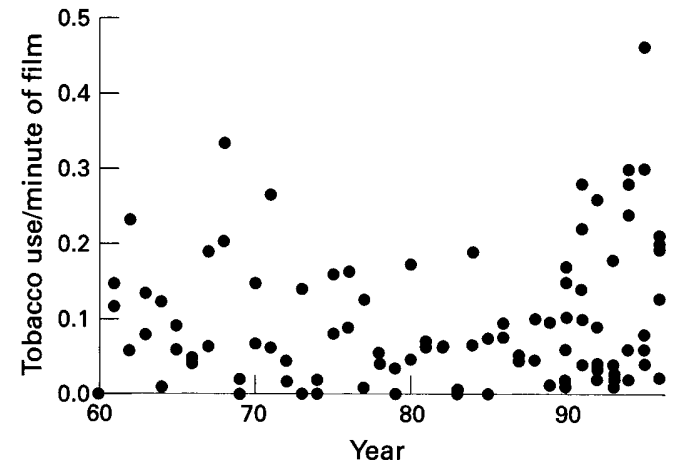

Figure 1 The rate at which tobacco appears in films (per minute of film) appears to have reached a minimum during the 1980 s and is now increasing. Tobacco is now used in films at rates comparable to the 1960 s.

part of the 1980s decade; in the present analysis, 1990-1996 was considered the 1990 s decade.)

\section{Results}

The 35 films in this study contained a total of 743 five-minute intervals (an average of 25 per film). Of the 876 five-minute intervals, 290 (33\%) contained some reference to tobacco. Excluding film credits, total viewing time for all 35 films was 4371 minutes, averaging 125 minutes each. Of the total running time, 175 minutes contained a tobacco incident (5 minutes per film, or $4 \%$ of running time). Of the 5 minutes per film, an average of only $43 \mathrm{~s}$ per film $(14 \%$ of all tobacco-related screen time) was devoted to an anti-tobacco message.

In our earlier study, ${ }^{1}$ we reported that the overall rate of tobacco use per minute of film appeared constant over the three decades we studied. Adding data from the 1990s changes this picture (figure 1). It now appears that tobacco use fell in the $1960 \mathrm{~s}$ and $1970 \mathrm{~s}$, reached a minimum in the $1980 \mathrm{~s}$, and is increasing in the $1990 \mathrm{~s}$.

In our earlier study, we reported a decline in smoking by major characters (the major protagonist and antagonist, regardless of gender) over the three decades, but the films still overestimated the prevalence of tobacco use in relation to comparable people in the population $^{3-9}$ (equivalent to college graduates based on their occupational status). The current study shows a similar pattern, with $57 \%$ of major characters smoking, compared with $14 \%$ of similar individuals in the general population smoking in the 1990s (figure 2). There may be an increasing discrepancy between the appearance of smoking in the movies and smoking in reality since 1991. Although none of the leads in our sample smoked in 1990, in 1991-1996, $80 \%$ of the male leads and $27 \%$ of female leads smoked.

The presence of smoking among major characters increased compared with the earlier decades. In the $1960 \mathrm{~s}, 38 \%$ of tobacco events involved major characters; this fraction fell to $29 \%$ in the 1970 s and $26 \%$ in the 1980 s. In the 1990 s, the fraction of tobacco events involving major characters increased to $51 \%(\mathrm{P}<0.001)$.

The social status of people in smoking incidents changed over the period of our study, from lower socioeconomic status in earlier dec-

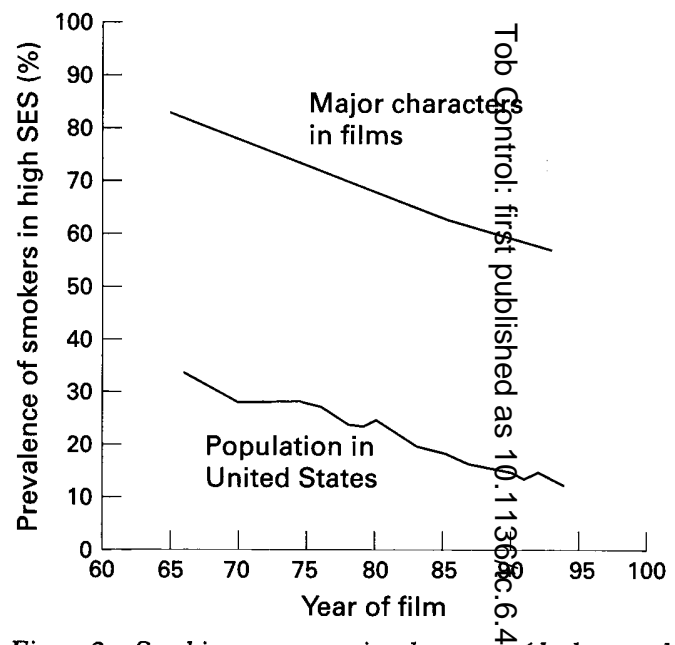

Figure 2 Smoking among major characte $\vec{\Delta}$ (the hero and villain) occurs at rates more than three timegothe rate among people of comparable socioeconomic status in society at large. ${ }^{3-9}$ The point for the 1990 s may underestimate the prevalence of smoking among major characters, because $80 \%$ of male leads smoked in the period 190-1996.

ades $(55 \%$ in the 1960 s, $54 \%$ in the 1970 s, and $58 \%$ in the 1980 s vs $21 \%$ in the 19 os) to middle $(19 \%, 25 \%, 25 \%$, and $49 \%$, respectively) and upper $(26 \%, 21 \%, 17 \%$, and tively) class $(\mathrm{P}<0.001)$. Cigarettes were involved in more of the tobacco events in the 1990 s $(75 \%)$ than in earlier desades $(50 \%$, $50 \%$, and $57 \%$, respectively) ( $\mathrm{P}<0 \overline{\mathrm{g}} 01)$. Brand identification fell off, consistent claims that brand placement is not actively encouraged..$^{14}$ More of the smoki involved whites in the 1990 s than in earlier decades $(93 \%$ in 1990 s vs $81 \%, 80 \%$ Fand $72 \%$ in earlier decades, $\mathrm{P}<0.001)$; smolking events involving African Americans remarised stable at about $4 \%$. Most smoking events throughout the period of our study? but there is a shift towards women using tobaôco (fraction of tobacco events involving men: $8 \%$ in $1960 \mathrm{~s}$, $94 \%$ in 1970 s, $79 \%$ in 1980 s, $66 \%$ in 1990 s; $\mathrm{P}<0.001$ ). In the 1990 s tobacco erents continued to be associated with relaxation and stress as in earlier decades ( $62 \%$ of event 5 in $1990 \mathrm{~s} v \mathrm{~s}$ $63 \%, 62 \%$, and $63 \%$ in earlier decodes).

\section{Discussion}

을.

In contrast to actual Americh smoking patterns, smoking in films is nowincreasing, with levels of tobacco use comparable to that observed in the 1960s (figure 1) OO $_{0}^{\omega}$ before the issuance of the US Surgeon Genneral's first report. Although at lower levels enjoying a resurgence on televession, too. ${ }^{22}$ Tobacco use among major 0 characters continues to be much more prevalent than in reality (figure 2). Moreover, the aserage value for the 1990 s may understate currestt trends, in which $80 \%$ (SE $8 \%$ ) of male leads and $27 \%$ (SE $9 \%$ ) of female leads in our sample smoked since 1991.

Our data are consistent with pFess reports. USA Today ${ }^{13}$ examined the top 10 grossing films in November 1996 and found all of them featured tobacco use. Of the 18 films in national distribution at the time, 17 featured tobacco use. 
There have also been reports in the media of increasing cigar usage in films. ${ }^{15}$ Our data also show increasing appearance of cigars in the 1990 s, particularly in the most recent films. Whereas there were so few cigars observed in the sample of 62 films from 1960-1990 in our earlier study, ${ }^{1}$ that we could not do a formal analysis, cigars were increasingly prominent in the 1990s. At least one film in our sample for each year beginning in 1990 featured cigars, and all five films in our 1996 sample (100\%) exhibited cigar use. Despite the fact that cigar use is much less common than cigarette use, it is strongly represented in the 1990s. Of total tobacco events in $1996,34 \%$ involved cigars.

The reason for the increase in tobacco use in films is not clear. The view that the films are merely reflecting society is not supported by the evidence; tobacco use in films, 1990-1996, is increasing at a time that it is still falling-or at least is not on the rise - in society at large. In addition, the presentation of smoking in the movies continues to be pro-tobacco, with only $14 \%$ of screen time dealing with tobacco presenting adverse social or health effects.

During the $1980 \mathrm{~s}$, the tobacco industry was paying substantial fees for product placement, such as the agreement between Sylvester Stallone and Brown and Williamson, in which $\mathrm{Mr}$ Stallone agreed to smoke Brown and Williamson brand cigarettes in six films for $\$ 500000 .^{23}$ The Tobacco Institute now claims that the practice of paying for cigarette brand placement has ended, ${ }^{14}$ although this statement avoids the possibility that tobacco companies are paying to place tobacco use in general. Indeed, the Los Angeles Times has reported that some people are paid to use tobacco. ${ }^{10}$

Films continue to present the smoker as one who is typically white, male, middle class, successful, and attractive, a movie hero who takes smoking for granted. As in tobacco advertising, ${ }^{24}$ tobacco use in the movies is associated with youthful vigour, good health, good looks, and personal and professional acceptance. Portrayals of tobacco use, whether in a positive or negative context, lead to changes in attitudes that predispose children to smoking. ${ }^{25}$ In an era in which the tobacco industry is finding traditional advertising media increasing restricted, the appearance of tobacco use in motion pictures is an important mechanism to promote and reinforce tobacco use, particularly among young people, who dominate the audience for popular films. For example, in Australia, which has all but eliminated traditional tobacco advertising and promotion, the Australian Medical Association has identified tobacco use in films as a major problem. ${ }^{26}$

The question of how to deal with this problem remains difficult, given concerns about free speech and the need for artistic freedom in making films. Nevertheless, the fact remains that films (and, to a lesser extent, television) are promoting tobacco use. There is also a lingering suspicion that the tobacco industry is playing an active role in encouraging the increase in tobacco use, as it did in past years. Pechmann and Shih ${ }^{25}$ have suggested that it is possible to "immunise" children against the pro-smoking influences of smoking in movies by showing a strong anti-tobacco advertisement before the feature film. Motion picture exhibitors should air such an advertisement in any films that include smoking to neutralise the pro-tobacco influences in the film. In addition, we suggest that producers require that everyone connected with the making of a film (including writers, directors, actors, and property masters) certify that they are not receiving any consideration (such as money, cars, or jewellery ${ }^{23}$ ) for the use of tobacco in the film. This certification could then be applied to the end of a film, just as many producers certify that "no animals were harmed in the making of this film" to assuage animal lovers.

Regardless of the reasons, the use of tobacco in films is increasing and is reinforcing misleading images that present smoking as a widespread and socially desirable activity. These portrayals may encourage teenagersthe major movie audience-to smoke. It also appears that the problem is getting worse.

This work was supported by NCI Grant CA-61021.

1 Hazan A, Lipton H, Glantz S. Popular films do not reflect current tobacco use Am f Public Health 1994;84:998-1000.

US Department of Health, Education, and Welfare. Smoking and Health: Report of the Advisory Committee to the Surgeon General of the Public Health Service. Washington, DC: Department of Health, Education and Welfare, 1964 (DHEW Publication No (PHS) 1103.)

3 US Department of Health and Human Services. Reducing the health consequences of smoking: 25 years of progress. $A$ report of the Surgeon General, 1989. Rockville, Maryland: Public Health Service, Centers for Disease Control, Office on Smoking and Health, 1989. (DHHS Publication No (CDC) 89-8411.)

4 US Centers for Disease Control. Cigarette smoking amon adults-United States, 1988. MMWR 1991;40:757-9, 765 (erratum 1992;41:367).

5 US Centers for Disease Control. Cigarette smoking amon adults-United States, 1990. MMWR 1994;41:354-5.

6 US Centers for Disease Control. Cigarette smoking amon adults-United States, 1991. MMWR 1994;42:230-3.

7 US Centers for Disease Control. Cigarette smoking among adults-United States, 1992, and changes in the definition of current cigarette smoking. MMWR 1994;43:342-5.

8 US Centers for Disease Control. Cigarette smoking among adults-United States, 1993. MMWR 1994;43:925-30.

9 US Centers for Disease Control and Prevention. Cigarette smoking among adults-United States, 1994. MMWR 1996;45:588-9.

10 Dutka E. Force of habit: where there's smoke, there's Holly wood. The portrayal of smoking on-screen goes on, much to the dismay of activists who are locked in battle with the tobacco industry. Los Angeles Times 1996 Sep 5.

11 Kalish D. Fewer Americans smoke, but Hollywood can't kick habit. Associated Press, 22 October 1996.

12 Thomas $\mathrm{K}$. No waiting to inhale: cigarettes light up the movies. USA Today 1996 Nov 7:D1

13 Thomas K. Lighting up: tobacco has a role in most movies. USA Today 1996 Nov 7:D6.

14 Thomas K. Hollywood's cigarette break of sorts. USA Today 1996 Nov 7:D6.

15 Meyer T. Cigar smoking by teens worries CDC. San fos (California) Mercury News 1997 May 23

16 Anon. Weekly box office report-US and Canada. Variety 1991 Jan 7:5.

17 Anon. Terminator 2 takes ring in $\$ 200$ mil year. Variety 1992 Jan 6:8.

18 Anon. Weekly box office report-US and Canada. Variety 1993 Jan 11:22.

19 Anon. Film grosses. Variety 1994 Jan 24:24.

20 Anon. The lowdown on 94's record box office heights. Variety 1995 Jan 30:17.

21 Anon. Box office performance of films in 1995 . Variety 1996 Jan 8:38.

22 Hazan A, Glantz S. Current trends in tobacco use on prime-time fictional television (letter). Am F Public Health 1995;85:116-7.

23 Glantz SA, Barnes DE, Bero L, Hanauer P, Slade J. The cigarette papers. Berkeley, California: University of California Press, 1996:219-24.

24 US Federal Trade Commission. Staff report on the cigarette advertising investigation. Washington, DC: Federal Trade Comming investigatio

25 Pechmann C, Shih C-F. How smoking in movies and anti-smoking ads before movies may affect teenagers'perceptions of peers who smoke. Irvine, California: Graduate School

26 Lamb E. Poll backs more curbs on smoking. Mercury (Hobart, Tasmania) 1996 Jul 23:12. 